\title{
Long-Term Efficacy of Lansoprazole in Preventing Relapse of Erosive Reflux Esophagitis
}

\author{
Thomas O. Kovacs · James W. Freston • \\ Marian M. Haber · Barbara Hunt • \\ Stuart Atkinson · David A. Peura
}

Received: 23 October 2008/Accepted: 11 February 2009/Published online: 7 March 2009

(c) The Author(s) 2009. This article is published with open access at Springerlink.com

\begin{abstract}
In a phase III study of lansoprazole treatment, patients with healed or unhealed erosive esophagitis entered a titrated open-label treatment period and received lansoprazole for $\leq 6$ years to assess long-term maintenance therapy. Doses were adjusted depending on symptom response. Endoscopy was performed yearly. One hundred ninety-five subjects received lansoprazole for $<1$ to 72 months; most received daily doses of $\leq 30 \mathrm{mg}$. Lansoprazole maintained erosive esophagitis remission in $75 \%$ of subjects receiving treatment for $\leq 72$ months, with 39 subjects experiencing 50 recurrences. Most subjects (94-95\%) had no or mild symptoms of day or night heartburn at study end, and 77\% were asymptomatic at first erosive esophagitis recurrence. The most common treatment-related adverse events included diarrhea (10\%), headache (8\%), and abdominal pain $(6 \%)$, and were mild or moderate in severity. Long-term lansoprazole is effective and well tolerated when used to maintain erosive esophagitis remission for $\leq 6$ years.
\end{abstract}

T. O. Kovacs $(\bowtie)$

VA Greater Los Angeles Healthcare System, CURE Digestive Diseases Research Center, Los Angeles, CA 90073, USA

e-mail: TKovacs@mednet.ucla.edu

J. W. Freston

University of Connecticut Health Center, Farmington, CT, USA

M. M. Haber

Department of Pathology, Drexel University College

of Medicine, Philadelphia, PA, USA

B. Hunt $\cdot$ S. Atkinson

Takeda Global Research \& Development Center, Inc., Deerfield, IL, USA

D. A. Peura

University of Virginia Health System, Charlottesville, VA, USA
Keywords Lansoprazole - Erosive esophagitis · Gastroesophageal reflux disease - GERD - Efficacy · Long-term maintenance therapy

\section{Introduction}

Gastroesophageal reflux disease (GERD) is a highly prevalent condition, affecting $10-30 \%$ of the adult population in Western countries [1] and utilizing significant healthcare resources [2]. When left untreated, or when treated inadequately, GERD can produce a spectrum of potentially severe complications [3-5]. One such complication is erosive esophagitis (EE), a chronic and relapsing condition associated with significant impairment in quality of life (QoL) [6]. Pharmacologic therapy is necessary for healing and effective control of symptoms in the majority of patients [7].

Proton pump inhibitors (PPIs) have emerged as highly effective treatment not only for rapid healing of EE and maintenance of remission [8], but also for symptomatic relief and improvement of QoL [9-11]. Within 1 year of initial healing, however, the majority of patients experience both EE relapse and recurrence of symptoms [5, 12-18]. These observations indicate that long-term maintenance therapy with a PPI is warranted to reduce the risk of relapse and provide continued symptomatic relief [14, 18]. However, there remains a paucity of data regarding the longterm ( $>12$ months) use of PPIs in patients with EE, particularly in the United States.

Lansoprazole has been studied extensively in a number of acid-related diseases [5], and a growing number of studies support its safety and clinical efficacy when used as long-term maintenance therapy to prevent $\mathrm{EE}$ relapse 
$[15,16,19-23]$. In this article, we report the results of the titrated open-label treatment period of a multicenter study conducted to evaluate the safety and efficacy of lansoprazole in the maintenance treatment of EE. The specific purposes of this long-term (up to 6 years) clinical trial were to assess the efficacy of lansoprazole in the prevention of EE relapse in recently healed patients and to evaluate the effectiveness of symptom-based dose titration in the management of EE and its symptoms.

\section{Methods}

\section{Study Design}

The focus of this article is the titrated open-label treatment portion of the M94-140 study (sponsored by Takeda Global Research \& Development Center, Inc., Deerfield, IL). This study was a randomized, parallel-group, multicenter, phase III study consisting of an 8-week open-label acute treatment period, a double-blind treatment period lasting up to 12 months, and a titrated open-label treatment period of up to 82 months (Fig. 1). Patients were enrolled at 19 sites within the US. The titrated open-label period began when the subject had a recurrence of EE or when they completed the double-blind treatment phase.

\section{Study Population}

The study population included male and female subjects aged $\geq 18$ years with endoscopically proven $\mathrm{EE}$ ( $\geq$ grade 2 ; Table 1) and without coexisting duodenal and/or gastric ulcer of $\geq 3 \mathrm{~mm}$ in diameter (within 7 days before initiating treatment). Subjects with Barrett's esophagus (but without dysplastic changes) were eligible to enter the study. Subjects requiring continuous treatment with digoxin or theophylline-containing drugs were permitted to enroll.

Subjects were excluded from enrollment for any of the following reasons: evidence of active comorbid illnesses; laboratory results outside normal limits; receipt of other investigational drug(s) within 12 weeks before initiating study medication; treatment with a PPI within 4 weeks before initiating study treatment; or requirement for more than occasional use ( $\leq 10$ days per month) of nonsteroidal anti-inflammatory drugs (NSAIDs) or corticosteroids equivalent to $>10 \mathrm{mg} /$ day prednisone.

After completing the acute treatment period, subjects with healed EE were eligible to participate in the doubleblind treatment period. Subjects who completed the double-blind treatment period without relapse, and those who experienced a recurrence of EE during this phase of the study, were eligible for inclusion in the titrated open-label treatment period.

\section{Treatment}

Subjects entering the titrated open-label treatment period without recurrence of EE after completing the double-blind treatment phase were given lansoprazole $15 \mathrm{mg}$ QD. Subjects who entered the titrated open-label treatment period due to recurrence of EE began treatment with lansoprazole $30 \mathrm{mg}$ QD for 8 weeks, at which point subjects returned to the study center for the evaluation of healing visit. Subjects not healed after 8 weeks had their dose increased until endoscopic evidence of healing was documented. Once healing occurred, subjects continued treatment with lansoprazole $15 \mathrm{mg}$ QD. During the remainder of the titrated open-label treatment period, lansoprazole doses could be titrated upward (based on recurrence of EE and/or symptoms) or downward as required. The dose of lansoprazole was titrated so that subjects received the minimum dose required to control their symptoms. Subjects received lansoprazole $30 \mathrm{mg}$ QD for recurrence of EE, regardless of whether or not the subject had symptoms. Lansoprazole doses could be divided; however, the total daily dose could not exceed $120 \mathrm{mg}$ without permission from the Sponsor. Each dose was to be taken in the morning before breakfast (unless directed otherwise by the investigator). Protocolrequired visits were scheduled and conducted every 12 months, and a final visit was conducted when a subject ceased participation in the study.

Fig. 1 Study design

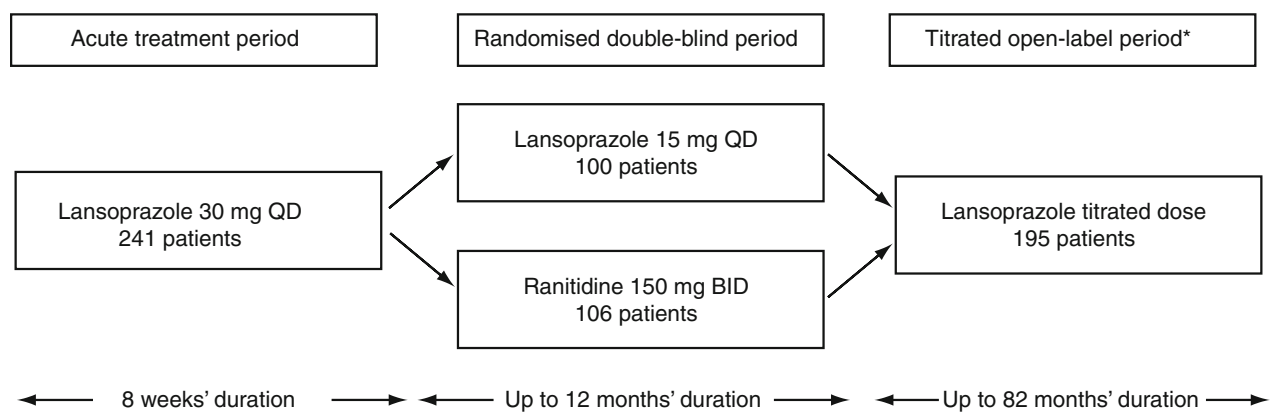


All anti-ulcer and anti-reflux agents (except antacids) must have been discontinued at least 7 days before the screening gastrin test, and anticholinergic medications must have been discontinued before the first dose of acutetreatment lansoprazole. Aspirin $\leq 325 \mathrm{mg} /$ day for cardiovascular indications was acceptable, and Gelusil ${ }^{\circledR}$ (Pfizer, NJ, USA) use was permitted for relief of symptoms.

To evaluate treatment compliance, subjects were required to return all unused study drug at each scheduled visit. All unused study drug was to be accounted for and reconciled between the label attachment form and the drug accountability form.

Assessments

\section{Efficacy}

The primary efficacy outcome was the time to recurrence of EE, as evaluated by endoscopy. Each study visit included an upper endoscopy using a modified Hetzel-Dent grading scale (Table 1) to document the presence or absence of EE.

Secondary efficacy outcomes included changes in the severity of primary (daytime and/or night-time heartburn) and secondary (gastroesophageal regurgitation, dysphagia, painful swallowing, nausea and vomiting, day and night abdominal pain, belching, fullness/bloating/early satiety, abdominal distension, anorexia, flatulence/abdominal rumbling) symptoms, and the number of Gelusil ${ }^{\circledR}$ tablets used. Time to recurrence of primary symptoms was also assessed. The investigator conducted an interview at each scheduled 12-month visit to determine the severity of symptoms experienced in the 2 weeks prior to the visit, assess symptom relief, and establish the number of Gelusil $^{\circledR}$ tablets taken since the previous visit.

\section{Safety}

Safety monitoring throughout the study entailed assessment of adverse events, vital signs, concurrent medications, and

Table 1 Esophagitis grading scale [12]

\begin{tabular}{ll}
\hline Grade & Description \\
\hline 0 & Normal-appearing mucosa by endoscopy \\
1 & Mucosal edema, hyperemia, and/or friability of mucosa \\
2 & One or more erosion(s)/ulceration(s) involving $<10 \%$ of the \\
& distal $5 \mathrm{~cm}$ of the esophagus \\
3 & Erosions/ulcerations involving $10-50 \%$ of the distal $5 \mathrm{~cm}$ of \\
& the esophagus, or an ulcer measuring $3-5 \mathrm{~mm}$ in diameter \\
4 & Multiple erosions/ulcerations involving $>50 \%$ of the distal \\
& $5 \mathrm{~cm}$ of the esophagus, or a single large ulcer measuring \\
& $>5 \mathrm{~mm}$ in diameter
\end{tabular}

(if applicable) digoxin and/or theophylline levels at each scheduled visit. Physical examinations, laboratory assessments (including gastrin), gastric biopsies, and serum pregnancy tests for female subjects were also conducted at each 12-month visit.

\section{Ethical Approval and Informed Consent}

All subjects were required to understand and sign the informed consent prior to screening and to understand and cooperate with study procedures. Prior to initiating any study procedures, each investigator site was granted approval by an Institutional Review Board. The study adhered to the ethical principles stated in the Declaration of Helsinki (1996 revision) and was conducted in accordance with Food and Drug Administration guidelines, Guidelines for Good Clinical Practice governing clinical study conduct, and all applicable local regulations.

\section{Statistical Methods}

All subjects who took at least one dose of lansoprazole and had efficacy measurements available were included in the efficacy analyses. The primary efficacy endpoint was time to recurrence of EE, which was summarized using lifetable methods. Five subjects who entered the titrated openlabel treatment period unhealed and subsequently had no documented healing were excluded from the analysis of recurrence. Confidence intervals (CIs) of $95 \%$ for the rates were obtained using the estimated standard error and assuming asymptomatic normality. The relationship between EE recurrence and various factors [age, body mass index (BMI; $>30$ or $\leq 30$ ), gender, race (white or nonwhite), tobacco use, alcohol use, EE grade at enrollment into the acute phase, as well as healing status, Helicobacter pylori (H. pylori) status, and symptom status at entry into the open-label treatment period] was explored using logistic regression.

Results of primary and secondary symptom assessments were presented as the number of subjects at each severity level for the symptom. The percentage of subjects remaining asymptomatic (no or mild day/night heartburn) during therapy was estimated using life-table methods for subjects who were asymptomatic at openlabel baseline. All subjects who took at least one dose of lansoprazole were included in the safety analyses. Adverse events, laboratory variables, and gastric biopsies were summarized.

SAS version 6.12 on the UNIX system (version 10.2 operating system) was used to perform the statistical analyses. All tests were two-sided, and $P$ values $\leq 0.05$ were considered significant. 


\section{Results}

Subjects

A total of 195 subjects with a mean age of 50.8 years entered the titrated open-label treatment phase. The majority of subjects were male $(131 / 195 ; 67 \%)$ and white $(176 / 195 ; 90 \%)$, and approximately half were experiencing recurrence of EE upon entry (102/195; 52\%) (Table 2). Enrollment of subjects into this treatment period began

Table 2 Subject demographics and baseline ${ }^{\mathrm{a}}$ characteristics $(N=195)$

\begin{tabular}{|c|c|}
\hline Parameter & Number of subjects \\
\hline \multicolumn{2}{|l|}{ Gender $n(\%)$} \\
\hline Male & $131(67)$ \\
\hline \multicolumn{2}{|l|}{ Race $n(\%)$} \\
\hline White & $176(90)$ \\
\hline Black & $13(7)$ \\
\hline Hispanic & $6(3)$ \\
\hline \multicolumn{2}{|l|}{ Age (years) } \\
\hline Mean $( \pm \mathrm{SD})$ & $50.8( \pm 13.8)$ \\
\hline Minimum-Maximum & $20-82$ \\
\hline \multicolumn{2}{|l|}{ Weight (males) } \\
\hline Mean $( \pm \mathrm{SD})$ & $199.6( \pm 33.0)$ \\
\hline Minimum-maximum & $131-299$ \\
\hline \multicolumn{2}{|l|}{ Weight (females) } \\
\hline Mean $( \pm \mathrm{SD})$ & $175.5(30.4)$ \\
\hline Minimum-maximum & $116-248$ \\
\hline \multicolumn{2}{|l|}{ Body mass index } \\
\hline Mean $( \pm \mathrm{SD})$ & $29.0(4.6)$ \\
\hline Minimum-maximum & $19-45$ \\
\hline \multicolumn{2}{|c|}{ Erosive reflux esophagitis grade at entry into acute phase $n(\%)$} \\
\hline Grade 2 & $110(56)$ \\
\hline Grade 3 & $68(35)$ \\
\hline Grade 4 & $17(9)$ \\
\hline \multicolumn{2}{|c|}{ Erosive reflux esophagitis grade at entry into open-label phase $n(\%)$} \\
\hline Healed & $93(48)$ \\
\hline Grade 0 & $74(38)$ \\
\hline Grade 1 & $19(10)$ \\
\hline Unhealed & $102(52)$ \\
\hline Grade 2 & $82(42)$ \\
\hline Grade 3 & $16(8)$ \\
\hline Grade 4 & $4(2)$ \\
\hline \multicolumn{2}{|l|}{ H. pylori status $N(\%)$} \\
\hline Negative & $155(80)$ \\
\hline
\end{tabular}

${ }^{a}$ At open-label baseline unless otherwise noted

$N$ Number of subjects evaluated; $n$ number of subjects in category; $H$. pylori Helicobacter pylori; SD: standard deviation
Table 3 Duration of lansoprazole exposure for all subjects during the titrated open-label treatment period

\begin{tabular}{ll}
\hline Duration of exposure & $\begin{array}{l}\text { All subjects }(N=195) \\
n(\%)\end{array}$ \\
\hline 12 months or less & $16(8.2)$ \\
$>12-24$ months & $15(7.7)$ \\
$>24-36$ months & $13(6.7)$ \\
$>36-48$ months & $10(5.1)$ \\
$>48-60$ months & $21(10.8)$ \\
$>60-72$ months & $57(29.2)$ \\
$>72$ months & $63(32.3)$
\end{tabular}

Duration of the study ranged from $<1$ month to 72 months

$N$ Number of subjects evaluated; $n$ Number of subjects exposed during interval

in February 1996 and ended in December 1997. While some subjects received lansoprazole for $>72$ months (Table 3), the data for this period are sparse; therefore, cumulative survival analysis rates are presented only through 72 months. Safety evaluations, however, are presented for the entire follow-up period and include those patients treated for $>72$ months.

Primary reasons for premature discontinuation in 105/ 195 (54\%) patients included adverse events (18/195; 9\%), personal issues $(13 / 195 ; 7 \%)$, poor compliance $(9 / 195$; $5 \%$ ), treatment with another drug that would interfere with evaluation of study drug $(7 / 195 ; 4 \%)$, pregnancy $(2 / 195$; $1 \%)$, and therapeutic failure $(1 / 195 ; 1 \%)$. Fifty-five $(28 \%)$ patients prematurely discontinued because of other reasons, including closure of study site or patient lost to follow-up. Two patients discontinued because they required fundoplication.

\section{Treatment}

During the titrated open-label treatment period, lansoprazole exposure ranged from $<1$ to $>72$ months, with 120 / $195(62 \%)$ patients receiving treatment for $>60$ months (Table 3). Total daily doses of lansoprazole ranged from $\leq 15 \mathrm{mg}$ to $120 \mathrm{mg}$, but most subjects received daily doses of $\leq 30 \mathrm{mg}$. Forty-five subjects received $60 \mathrm{mg}$ or more of lansoprazole per day at some time during the open-label period. During the open-label treatment period, $65 \%(126 / 195)$ of subjects increased their dosage from the maintenance dose (15 mg daily) at least once, either due to an endoscopically documented relapse of $\mathrm{EE}$ or to alleviate symptoms. At the final titration, the total daily dose was $>30 \mathrm{mg}$ of lansoprazole in 19\% (37/195) of subjects. The percentage of patients within each dose category at the end of each treatment year is presented in Fig. 2. 
Fig. 2 Distribution of lansoprazole doses at the end of each treatment year

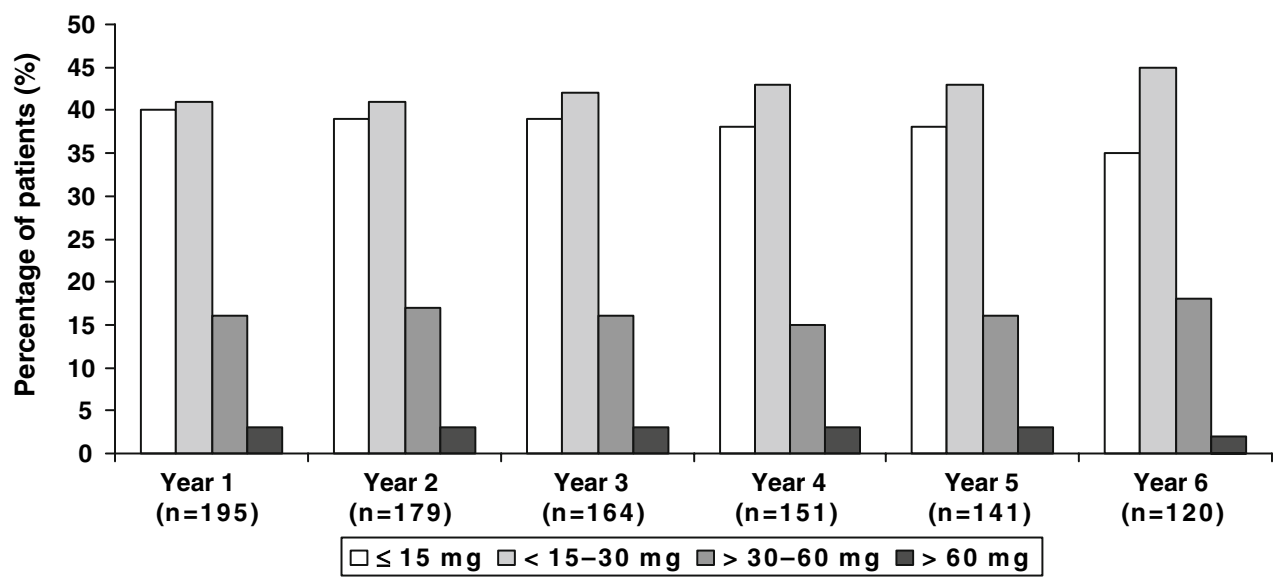

\section{Efficacy}

\section{Maintenance of Healing}

Lansoprazole was effective in maintaining remission of $\mathrm{EE}$ in $75 \%$ of subjects receiving long-term open-label therapy (up to 72 months) (Table 4); during the entire titrated openlabel treatment period (up to 82 months), 39 subjects experienced a total of 50 recurrences of EE. All recurrences of EE were grade 2. Logistic regression analysis suggested that healing status (healed vs. unhealed) at open-label baseline was predictive of $\mathrm{EE}$ relapse (odds ratio $=0.46$; $95 \% \mathrm{CI}=0.22,0.97)$, with subjects healed at open-label baseline less likely to relapse during the titrated open-label treatment period. No other demographic or baseline factors were found to be predictive of EE recurrence.

When $H$. pylori status at open-label baseline was considered, life-table analysis suggested that $H$. pylori-positive subjects were more likely to remain healed through 72 months of therapy (85\%) than $H$. pylori-negative counterparts $(73 \%)$ (Table 4). However, H. pylori status was not found to be predictive of EE recurrence in the logistic regression analysis.

\section{Symptom Assessment}

At open-label baseline, 125/194 (64\%) and 110/194 (57\%) subjects experienced primary symptoms of daytime or night-time heartburn, respectively. At the final visit, however, the majority of subjects assessed had no or only mild symptoms of daytime $(175 / 185 ; 95 \%)$ or night-time heartburn (174/185; 94\%) (Table 5). Most subjects (30/39; $77 \%$ ) were also asymptomatic at the time of their first recurrence of EE. Life-table analysis showed that $68 \%$ of patients who had no primary symptoms at open-label baseline would remain asymptomatic through 72 months of

Table 4 Proportion of subjects remaining healed ${ }^{\mathrm{a}}$ during the titrated open-label $(\mathrm{OL})$ treatment period

\begin{tabular}{lllllll}
\hline Months & $0-12$ & $12-24$ & $24-36$ & $36-48$ & $48-60$ & $60-72$ \\
\hline All treated subjects $(N=190)^{\mathrm{b}}$ & $n=178$ & $n=154$ & $n=126$ & $n=114$ & $n=99$ & $n=64$ \\
Remaining healed $(\%)$ & 93 & 85 & 81 & 80 & 77 & 75 \\
95\% CI & - & $80.1,90.7$ & $75.4,87.3$ & $73.7,86.1$ & $70.9,84.0$ & $67.9,82.2$ \\
H. pylori-positive subjects $(n=39)$ & $n=39$ & $n=32$ & $n=27$ & $n=23$ & $n=20$ & $n=14$ \\
Remaining healed (\%) & 97 & 91 & 85 & 85 & 85 \\
95\% CI & - & $81.9,100.0$ & $72.0,97.1$ & $72.0,97.1$ & $72.0,97.1$ \\
H. pylori-negative subjects $(n=151)$ & $n=139$ & $n=122$ & $n=99$ & $n=91$ & $n=79$ \\
Remaining healed $(\%)$ & 92 & 84 & 80 & 79 & $76.0,97.1$ \\
95\% CI & - & $77.6,90.0$ & $73.6,87.2$ & $71.6,85.7$ & $68.1,83.2$ & $64.3,81.0$
\end{tabular}

${ }^{a}$ Counted from the first day of OL treatment for subjects entering the OL period healed and from the day of healing in the titrated OL treatment period for subjects who entered unhealed. The subject was considered as remaining healed within the interval if esophagitis remained at grade 0 1; cumulative interval rates were calculated based on life-table methods, which calculate the rates based on exposure during successive intervals

b Number of subjects considered exposed during the first interval (0-12 months) differs from the number of subjects who entered OL treatment because of patient withdrawal prior to the midpoint of the interval

H. pylori Helicobacter pylori; CI confidence interval 
Table 5 Changes in primary and secondary symptom severity from open-label baseline to the final visit of the titrated open-label treatment period

\begin{tabular}{|c|c|c|c|c|c|c|c|}
\hline & \multirow{2}{*}{\multicolumn{2}{|c|}{$\begin{array}{l}\text { Symptom severity at } \\
\text { open-label baseline } n\end{array}$}} & \multicolumn{5}{|c|}{ Symptom severity at the final visit of titrated open-label treatment period $n$} \\
\hline & & & None & Mild & Moderate & Severe & Missing \\
\hline \multicolumn{8}{|l|}{ Primary symptoms } \\
\hline \multirow[t]{5}{*}{ Daytime heartburn $N=194$} & None & 69 & 53 & 10 & 2 & 0 & 4 \\
\hline & Mild & 47 & 28 & 14 & 2 & 0 & 3 \\
\hline & Moderate & 51 & 29 & 16 & 5 & 0 & 1 \\
\hline & Severe & 27 & 18 & 7 & 0 & 1 & 1 \\
\hline & Total & 194 & 128 & 47 & 9 & 1 & 9 \\
\hline \multirow[t]{5}{*}{ Night-time heartburn $N=194$} & None & 84 & 70 & 8 & 2 & 1 & 3 \\
\hline & Mild & 27 & 15 & 9 & 1 & 0 & 2 \\
\hline & Moderate & 54 & 33 & 14 & 4 & 0 & 3 \\
\hline & Severe & 29 & 12 & 13 & 3 & 0 & 1 \\
\hline & Total & 194 & 130 & 44 & 10 & 1 & 9 \\
\hline \multicolumn{8}{|l|}{ Secondary symptoms } \\
\hline \multirow[t]{5}{*}{ Overall signs and symptoms $N=193$} & None & 24 & 13 & 8 & 2 & 0 & 1 \\
\hline & Mild & 82 & 35 & 38 & 4 & 0 & 5 \\
\hline & Moderate & 73 & 23 & 42 & 6 & 0 & 2 \\
\hline & Severe & 14 & 4 & 6 & 1 & 1 & 2 \\
\hline & Total & 193 & 75 & 94 & 13 & 1 & 10 \\
\hline
\end{tabular}

$N$ Number of subjects evaluated; $n$ number of subjects at severity level

lansoprazole treatment. The percentage of subjects remaining asymptomatic was similar between the $H$. pylori-positive and $H$. pylori-negative subjects. Through 72 months of treatment, $72 \%$ of $H$. pylori-positive subjects were asymptomatic compared to $67 \%$ of $H$. pylori-negative subjects.

Although not statistically significant, a higher proportion of subjects who were asymptomatic at open-label baseline remained relapse-free $(78 / 142 ; 55 \%)$ throughout the openlabel period compared with subjects who were symptomatic at baseline $(64 / 142 ; 45 \%)$.

Improvements in secondary symptoms (gastroesophageal regurgitation; dysphagia; painful swallowing; nausea and vomiting; day and night abdominal pain; belching; fullness/bloating/early satiety; abdominal distension; anorexia; flatulence/abdominal rumbling) were also noted. In total, 111/169 (66\%) subjects reported overall symptom improvement compared with open-label baseline, with 169/ $183(92 \%)$ subjects experiencing no or mild secondary symptoms at the final visit (Table 5).

\section{Gelusil $^{\circledR}$ Use}

The majority of subjects $(179 / 195 ; 92 \%)$ used Gelusil $^{\circledR}$ during the titrated open-label treatment period. The median number of Gelusil ${ }^{\circledR}$ tablets taken per week was 0.5.
Safety

Overall, 69/195 (35\%) patients experienced an adverse event that was considered to be at least possibly related to the study drug. Most treatment-related adverse events were self-limiting and did not result in early discontinuation of treatment. The most common treatment-related adverse events (i.e., those experienced by at least $5 \%$ of subjects) were mild or moderate in severity and included diarrhea $(19 / 195 ; 10 \%)$, headache $(16 / 195 ; 8 \%)$, and abdominal pain $(12 / 195 ; 6 \%)$. One subject died during open-label treatment (accidental injury), and two subjects died during the follow-up period (one subject died 432 days after discontinuing treatment due to complications of amyotrophic lateral sclerosis and one subject died approximately 10 months after discontinuing treatment due to cardiogenic shock secondary to an acute myocardial infarction). All deaths were considered by the investigator to be unrelated to the study drug.

Consistent with findings from other studies investigating PPIs, gastric body and antral biopsies demonstrated neither increased severity of chronic gastritis nor progression to intestinal metaplasia and/or atrophy. At open-label baseline, 153/179 (85\%) of subjects had evidence of chronic inflammation in gastric body biopsies; at the final visit, $54 \%(82 / 153)$ of subjects with evidence of chronic 
inflammation at baseline showed improvement [18\% (27/ 153 ) of which completely resolved], 55/153 (36\%) were unchanged, and 16/153 (10\%) were worsened. A total of $152 / 179(85 \%)$ subjects had evidence of chronic inflammation in antral biopsies at open-label baseline, with 83/ $152(55 \%)$ subjects showing improvement [of which 13/ $152(9 \%)$ showed complete resolution], 60/152 (39\%) were unchanged, and $9 / 152(6 \%)$ were worsened at the final visit.

Among $H$. pylori-positive subjects with active gastric body inflammation at open-label baseline, 18/34 (53\%) improved at the final visit; $21 / 32(66 \%)$ with active gastric antrum inflammation improved. In the $H$. pylori-negative group, 6/6 (100\%) subjects with active gastric body inflammation improved compared to $11 / 12$ (92\%) with active gastric antrum inflammation. For $H$. pylori-positive subjects with chronic inflammation at baseline, improvement was found in 15/38 (39\%) of subjects with gastric body inflammation compared with 18/39 (46\%) with gastric antrum inflammation. In the $H$. pylori-negative group, 67/115 (58\%) with chronic gastric body inflammation improved compared with 65/113 (58\%) with gastric antrum inflammation.

Intestinal metaplasia in the gastric body and antrum was present in $3 \%$ and $22 \%$ of subjects, respectively, at one or more visits during the titrated open-label treatment period. Atrophy in the antrum and gastric body was seen in a minority of subjects [5.6\% (11/195) and 1.5\% [3/195], respectively] and showed no significant increase during the course of the study. There were no subjects with endocrine cell dysplasia or neoplasia; however, as expected, endocrine hyperplasia (four simple, two linear or micronodular) associated with PPI-induced hypergastrinemia was observed in six subjects at the final visit.

\section{Discussion}

The results of this study demonstrate the long-term efficacy and safety of lansoprazole treatment for maintenance of EE remission. Symptom-based lansoprazole dose titration provided sustained remission of EE in $75 \%$ of subjects for up to 72 months; healing status (healed or unhealed) at open-label baseline was identified by multiple logistic modeling as an important predictive factor for EE recurrence. No other demographic or baseline factors were found to be significant predictors of EE relapse. Most subjects also experienced substantial improvements in primary and secondary symptoms, and analyses using lifetable methodology suggested that $68 \%$ of subjects who had no primary symptoms at open-label baseline remained asymptomatic through 72 months of lansoprazole treatment. However, subjects with symptoms present at open- label baseline were more likely to relapse throughout the maintenance period-an observation that may have important clinical implications, as a lack of symptoms might predict a lack of EE recurrence.

Lansoprazole was generally well tolerated. As can be expected in a study of up to 6 years' duration, a relatively high proportion of patients $(35 \%)$ experienced treatmentrelated adverse events; however, most such events were mild or moderate in severity, and the most commonly experienced events were consistent with those previously reported in trials assessing lansoprazole use.

Numerous studies have assessed the efficacy of maintenance PPI therapy (esomeprazole, lansoprazole, omeprazole, pantoprazole, and rabeprazole) in patients with EE. One meta-analysis included 22 randomized controlled trials (RCTs) in which healing and maintenance PPI doses were compared for efficacy in maintaining EE remission; a total of 5,964 patients were analyzed, 1,527 (30\%) of whom presented with initially severe EE. Healing doses were generally defined as the standard dose recommended by the manufacturer, while maintenance doses were defined as half the standard dose. At the end of follow-up, which ranged from 24 to 52 weeks, the frequency of EE relapse was significantly lower among patients treated with a healing dose of a PPI [relative risk $(\mathrm{RR})=0.63$; 95\% CI 0.55-0.73] [8].

The same meta-analysis evaluated 18 RCTs that compared maintenance with healing doses of PPIs in maintaining symptom relief. A total of 5,116 patients were assessed, with a follow-up period of 26-52 weeks. The percentage of patients experiencing symptom recurrence was significantly lower for those treated with a healing dose of a PPI than for those receiving maintenance doses $(\mathrm{RR}=0.78 ; 95 \%$ CI 0.68-0.88) [8]. These results led to the suggestion that PPIs taken at a standard dose for a period of 6 months to 1 year may be more effective than lower maintenance doses in preventing $\mathrm{EE}$ relapse and recurrence of symptoms [24]. In contrast, the current study provides evidence that maintenance treatment with lansoprazole at doses lower than the standard dose of $30 \mathrm{mg}$ may be highly effective at maintaining EE remission and preventing symptom recurrence for up to 6 years.

Throughout the course of the current study, 65\% (126/ 195) of the subjects did increase their lansoprazole dose from the maintenance dose (15 mg daily) at least once, either due to an endoscopically documented relapse of EE or to alleviate symptoms. However, this is perhaps not surprising, as the study population included predominantly H. pylori-negative patients who had high BMIs and a high risk for recurrence of esophagitis and EE symptoms. Furthermore, the use of higher-than-maintenance doses for continuous maintenance treatment has been supported by a meta-analysis from Donnellan and colleagues, who found 
that healing doses of PPIs were significantly more effective at preventing EE relapse than maintenance doses [8].

Several published studies have investigated the efficacy of long-term lansoprazole in maintaining remission of EE and its symptoms [15, 16, 19-23], yet only one study to date has assessed lansoprazole maintenance therapy for more than 12 months [21]. In this study, 73 subjects with EE were treated with lansoprazole $30 \mathrm{mg}$ and followed for 5 years; $86 \%$ remained in remission at the end of the study [21]. The titrated open-label treatment phase of the current study has the advantage of a larger patient population ( $n=195$ ) and a longer follow-up period (up to 6 years), and is unique in its use of symptom-based dose titration.

Our results also suggest that $H$. pylori-positive subjects tended to have a greater likelihood of remaining healed throughout the study duration than their $H$. pylori-negative counterparts ( $85 \%$ and $73 \%$, respectively). The higher rates of EE remaining healed in $H$. pylori-positive subjects may be attributable to the observation that $H$. pylori enhances the acid-suppressive effects of PPIs, thus raising intragastric $\mathrm{pH}$ to a higher level. The mechanism for this phenomenon remains to be elucidated, but may involve $H$. pylori-induced corpus gastritis, which impairs parietal cell function [25]. However, the percentage of subjects who were asymptomatic at the end of the study was similar in the $H$. pylori-positive and -negative groups.

One weakness of the current study is its open-label design with lack of a comparator. However, this study is unique in that symptom-based dose titration was used; it also had a longer duration than similar trials, and so provides a more accurate reflection of clinical practice in the context of a real-world setting. Similarly, though most subjects used Gelusil ${ }^{\circledR}$ for symptom relief, the median number of weekly tablets used was low (0.5). Given the high relapse rate associated with discontinuation of PPI therapy [5, 13, 14, 17, 18], our findings enhance and strengthen the literature supporting the tolerability and clinical effectiveness of long-term lansoprazole in maintaining healing and symptom control of patients with EE.

In conclusion, long-term lansoprazole treatment effectively maintains EE remission and controls symptoms. It is well-tolerated when used for up to 6 years.

Acknowledgments This study (M94-140) was funded in full by Takeda Global Research \& Development Center, Inc. (TAP Pharmaceutical Products Inc. is now a part of Takeda Global Research \& Development Center, Inc.) Dr. Kovacs confirms that he has no conflicts of interest or disclosures. Dr. Freston has served as a consultant for Takeda Global Research \& Development Center, Inc., Takeda Pharmaceuticals North America, Inc., GlaxoSmithKline, and EnteroMedics, Inc. Dr. Haber serves as a consultant for Takeda Global Research \& Development Center, Inc. Dr. Peura serves as a consultant for Takeda Global Research \& Development Center, Inc. and as a member of the speaker's bureau for Takeda Pharmaceuticals North
America, Inc. Ms. Hunt and Dr. Atkinson are employees of Takeda Global Research \& Development Center, Inc.

Open Access This article is distributed under the terms of the Creative Commons Attribution Noncommercial License which permits any noncommercial use, distribution, and reproduction in any medium, provided the original author(s) and source are credited.

\section{References}

1. Holtmann G. Understanding GERD symptoms in the clinical setting. Drugs Today (Barc). 2005;41(Suppl. B):13-17. doi: 10.1358/dot.2005.41.1.875775. Barc.

2. Holtmann G, Adam B, Liebregts T. Review article: the patient with gastro-esophageal reflux disease-lifestyle advice and medication. Aliment Pharmacol Ther. 2004;20(Suppl. 8):24-27. doi:10.1111/j.1365-2036.2004.02224.x.

3. Featherstone EA. Severe GERD: effective treatment prevents potentially serious complications. JAAPA. 2005;18:25-29.

4. Fennerty MB. The continuum of GERD complications. Cleve Clin J Med. 2003;70(Suppl. 5):S33-S50.

5. Freston JW, Jackson RL, Huang B, Ballard ED. Lansoprazole for maintenance of remission of erosive esophagitis. Drugs. 2002;62: 1173-1184. doi:10.2165/00003495-200262080-00004.

6. Spechler SJ. Epidemiology and natural history of gastrooesophageal reflux disease. Digestion. 1992;51(Suppl. 1):24-29.

7. Kinoshita Y. Review article: treatment for gastro-esophageal reflux disease-lifestyle advice and medication. Aliment Pharmacol Ther. 2004;20(Suppl. 8):19-23. doi:10.1111/j.1365-2036. 2004.02223.x.

8. Donnellan C, Sharma N, Preston C, Moayyedi P. Medical treatments for the maintenance therapy of reflux oesophagitis and endoscopic negative reflux disease. Cochrane Database Syst Rev. 2005;CD003245.

9. Mathias SD, Castell DO, Elkin EP, Matosian ML. Health-related quality of life of patients with acute erosive reflux esophagitis. Dig Dis Sci. 1996;41:2123-2129. doi:10.1007/BF02071390.

10. Mulder CJ, Dekker W, Gerretsen M. Lansoprazole $30 \mathrm{mg}$ versus omeprazole $40 \mathrm{mg}$ in the treatment of reflux oesophagitis grade II, III and IVa (a Dutch multicentre trial). Dutch Study Group. Eur J Gastroenterol Hepatol. 1996;8:1101-1106. doi:10.1097/ 00042737-199611000-00013.

11. Richter JE, Kahrilas PJ, Sontag SJ, Kovacs TO, Huang B, Pencyla JL. Comparing lansoprazole and omeprazole in onset of heartburn relief: results of a randomized, controlled trial in erosive esophagitis patients. Am J Gastroenterol. 2001;96:30893098. doi:10.1111/j.1572-0241.2001.05263.x.

12. Hetzel DJ, Dent J, Reed WD, et al. Healing and relapse of severe peptic esophagitis after treatment with omeprazole. Gastroenterology. 1988;95:903-912.

13. Labenz J, Armstrong D, Lauritsen K, et al. Esomeprazole $20 \mathrm{mg}$ vs. pantoprazole $20 \mathrm{mg}$ for maintenance therapy of healed erosive esophagitis: results from the EXPO study. Aliment Pharmacol Ther. 2005;22:803-811. doi:10.1111/j.1365-2036. 2005.02643.x.

14. Lauritsen K, Devière J, Bigard MA, et al. Esomeprazole $20 \mathrm{mg}$ and lansoprazole $15 \mathrm{mg}$ in maintaining healed reflux esophagitis: metropole study results. Aliment Pharmacol Ther. 2003;17 (Suppl. 1):24-27. doi:10.1046/j.1365-2036.17.s1.7.x.

15. Robinson M, Lanza F, Avner D, Haber M. Effective maintenance treatment of reflux esophagitis with low-dose lansoprazole. A randomized, double-blind, placebo-controlled trial. Ann Intern Med. 1996;124:859-867. 
16. Sontag SJ, Kogut DG, Fleischmann R, Campbell DR, Richter J, Haber M. Lansoprazole prevents recurrence of erosive reflux esophagitis previously resistant to H2-RA therapy. The lansoprazole maintenance study group. Am J Gastroenterol. 1996;91: $1758-1765$.

17. Thjodleifsson B, Beker JA, Dekkers C, Bjaaland T, Finnegan V, Humphries TJ. Rabeprazole versus omeprazole in preventing relapse of erosive or ulcerative gastroesophageal reflux disease. Dig Dis Sci. 2000;45:745-753. doi:10.1023/A:1005548318996.

18. Tytgat GN. Review article: long-term use of proton pump inhibitors in GERD-help or hindrance? Aliment Pharmacol Ther. 2001;15(Suppl. 2):6-9. doi:10.1046/j.1365-2036.2001. 00115.x.

19. Baldi F, Morselli-Labate AM, Cappiello R, Ghersi S. Italian lansoprazole study group: daily low-dose versus alternate day fulldose lansoprazole in the maintenance treatment of reflux esophagitis. Am J Gastroenterol. 2002;97:1357-1364. doi:10.1111/ j.1572-0241.2002.05666.x.

20. Carling L, Axelsson C, Forsell H, et al. Lansoprazole versus omeprazole in long term maintenance treatment of refluxoesophagitis: a Scandinavian multicentre trial. Gut. 1996; 39((Suppl. 3)):182. Abstract.

21. Geboes K, Dekker W, Mulder CJ, Nusteling K. Dutch study group: long-term lansoprazole treatment for gastro-esophageal reflux disease: clinical efficacy and influence on gastric mucosa. Aliment Pharmacol Ther. 2001;15:1819-1826. doi:10.1046/ j.1365-2036.2001.01105.x.

22. Hatlebakk JG, Berstad A. Lansoprazole 15 and $30 \mathrm{mg}$ daily in maintaining healing and symptom relief in patients with reflux esophagitis. Aliment Pharmacol Ther. 1997;11:365-372. doi: 10.1046/j.1365-2036.1997.144320000.x.

23. Poynard T, Staub JL, Lemerez M, Deltenre M, Rekacevicz C, Sallerin V. Efficacy and safety of lansoprazole $15 \mathrm{mg}$ OAD or $30 \mathrm{mg} \mathrm{OAD}$ as one year maintenance treatment for erosive reflux esophagitis: a randomized trial. Gastroenterology. 1995; 108(Suppl):A195. doi:10.1016/0016-5085(95)23441-1. Abstract.

24. Ip S, Bonis P, Tatsioni A, Raman G, Chew P, Kupelnick B, et al. Comparative Effectiveness of Management Strategies for Gastroesophageal Reflux Disease. Evidence Report/Technology Assessment No. 1. (Prepared by Tufts-New England Medical Center Evidence-based Practice Center under Contract No. 29002-0022.) Rockville, MD: Agency for Healthcare Research and Quality. December 2005. Available at: http://effectivehealth care.ahrq.gov/repFiles/GERD\%20Final\%20Report.pdf. Accessed 25 April 2007.

25. Kuipers EJ, Klinkenberg-Knol EC, Meuwissen SG. Helicobacter pylori, proton pump inhibitors and gastroesophageal reflux disease. Yale J Biol Med. 1999;72:211-218. 